\title{
Developing a Benzimidazole-Silica-Based Hybrid Sol-Gel Coating with Significant Corrosion Protection on Aluminum Alloys 2024-T3 ${ }^{+}$
}

\author{
Magdi H. Mussa ${ }^{1,2,3, * \mathbb{C}}$, F. Deeba Zahoor ${ }^{3,4}$, Oliver Lewis ${ }^{3}$ and Nicholas Farmilo ${ }^{3,5}$ \\ 1 Mechanical and Energy Department, The Libyan Academy for Graduate Study, Tripoli P.O. Box 79031, Libya \\ 2 Mechanical Engineering Department, Sok Alkhamis Imsehel High Tec. Institute, Tripoli P.O. Box 79031, Libya \\ 3 Materials and Engineering Research institute MERI, Sheffield Hallam University, Howard Street, \\ Sheffield S1 1WB, UK; F.Zahoor@sheffield.ac.uk (F.D.Z.); O.Lewis@shu.ac.uk (O.L.); \\ nfarmilo@gmail.com (N.F.) \\ 4 Department of Chemistry, University of Sheffield, Sheffield S10 2TN, UK \\ 5 Tideswell Business Development Ltd., Ravensfield Sherwood Rd, Buxton SK17 8HH, UK \\ * Correspondence: magdimosa1976@gmail.com; Tel.: +44-7404496955 \\ + Presented at 8th International Electronic Conference on Sensors and Applications, 1-15 November 2021; \\ Available online: https:/ / ecsa-8.sciforum.net.
}

check for updates

Citation: Mussa, M.H.; Zahoor, F.D.; Lewis, O.; Farmilo, N. Developing a Benzimidazole-Silica-Based Hybrid Sol-Gel Coating with Significant Corrosion Protection on Aluminum Alloys 2024-T3. Eng. Proc. 2021, 11, 3. https://doi.org/10.3390/ASEC202111124

Academic Editor: Nicholas Vassiliou Sarlis

Published: 15 October 2021

Publisher's Note: MDPI stays neutral with regard to jurisdictional claims in published maps and institutional affiliations.

Copyright: (C) 2021 by the authors Licensee MDPI, Basel, Switzerland. This article is an open access article distributed under the terms and conditions of the Creative Commons Attribution (CC BY) license (https:// creativecommons.org/licenses/by/ $4.0 /)$.

\begin{abstract}
The inherent reactivity of $\mathrm{Al}-\mathrm{Cu}-\mathrm{Mg}$ alloys is such that their use for building structural, maritime, and airplane components with great strength/weight ratios would not be possible without good anti-corrosion systems. These systems could be considered as imitations of the protection mechanism found in the conventional hexavalent chromium-based system, but with additional limited environmental impact, and in particular without toxic or carcinogenic effects. These coatings also are intended to be eco-friendly, using less of the valuable raw materials and energy than more traditional methods. Silica-based hybrid protective coatings have been shown to exhibit excellent chemical stability combined with the ability to reduce the corrosion of metal substrates. However, research shows that sol-gel has some limitations in terms of the period of the anti-corrosive properties. Therefore, this work reports the performance of a silica-based hybrid sol-gel coating encapsulated with benzimidazole (BZI) that can be applied to light alloys to form an inherently inhibited and crack-free coating. This coating was applied on AA 2024-T3 and cured at $80{ }^{\circ} \mathrm{C}$. The high corrosion resistance performance results from the combination of good adhesion, the hydrophobic property of the silica-based hybrid coating, and the presence of the encapsulated (BZI) film-forming volatile corrosion inhibitor, which is released at pores within the coating system, resulting in film-forming, reducing the reaction at cathodic sites. The evaluation of this mechanism is based on using electrochemical testing techniques. The anti-corrosion properties of the coatings were studied when immersed in $3.5 \% \mathrm{NaCl}$ by using electrochemical impedance spectroscopy (EIS) and potential-dynamic polarization scanning (PDPS). The chemical confirmation was performed by infrared spectroscopy (ATR-FTIR), supported by analyzing the morphology of the surface before and after the immersion testing by using scanning electron microscopy (SEM). The benzimidazolesilica-based hybrid coating exhibited excellent anti-corrosion properties, providing an adherent protective film on the aluminum alloy 2024-T3 samples compared to sol-gel-only and bare metals, as a cost-effective and eco-friendly system.
\end{abstract}

Keywords: silica-based hybrid sol-gel coating; electrochemical testing; corrosion protection; aluminum alloys

\section{Introduction}

Silica-based hybrid protective coatings using sol-gel technology have shown an exceptional ability to reduce corrosion on the metal surface combined with high chemical 
stability. However, using the sol-gel technique alone has some limitations in terms of barrier anti-corrosive properties due to pores in the matrix, which could lead to cracking of the coating. The use of encapsulated corrosion inhibitors will enhance the system's corrosion protection. The systematic development of corrosion inhibitor compounds has produced many effective inhibitors. For example, compounds with heterocyclic organic functional groups consisting of oxygen or nitrogen, with phosphorus or sulfur attached as heteroatoms, are very desirable [1,2].

For instance, benzimidazole (BZI) (structure shown in Figure 1) has been identified as a low-pH film-forming effective corrosion inhibitor used for copper and steel. It possesses a heterocyclic aromatic organic compound structure that is suitable as both an effective volatile or injectable corrosion inhibitor with other soluble carriers. It has a chemical structure containing both a benzene group and the active group imidazole used in oil and gas production [3].

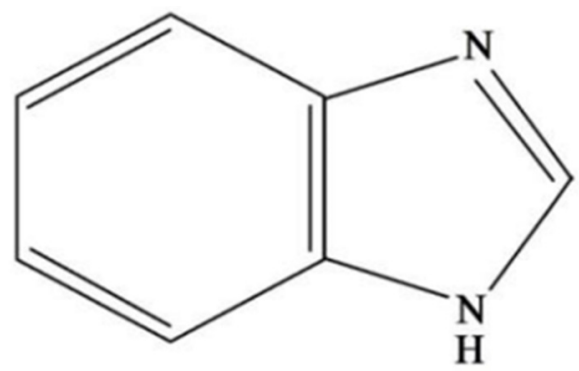

Figure 1. The chemical structure of benzimidazole (BZI).

The main advantages are that BZI is commercially available and cost-effective as a raw material for various uses, the most common of which is as a fungicide in pharmaceutical applications [4]. In addition, BZI derivatives are used in various corrosion applications in applied science. For example, Antonijevic et al. [2] described it as a powerful inhibitor that showed excellent corrosion prevention to protect carbon steel pipelines in corrosive acidic $\mathrm{HCl}$ solutions $[2,5]$.

The mechanism of inhibition by BZI or its derivatives on metal has been studied deeply, especially on copper and steel [5-7]. Furthermore, it has been found that BZI and its derivatives may be positioned in a parallel adsorption arrangement, a close joining with the surface, creating a thin layer. The adsorption of BZI in this position may be due to the donation of the $\pi$ electron on the BZI's nitrogen atoms to the unoccupied D-orbital, balancing the benzimidazole molecules with excited iron or copper atoms $[5,6]$. These interactions explain the strong adsorption connection to the surface that protects the mild steel or copper from direct corrosion $[5,6]$.

Related research has mentioned the use of BZI chemistries and related derivatives and patents: J. Colreavy et al. and S. Vijaykumar et al. mentioned using the same family of these inhibitors in their patented sol-gel technique on steel or other metals. This work demonstrated the specific application of BZI as a simple silica-based sol-gel additive used as a corrosion inhibitor for aluminum alloy AA2024-T3 [8,9].

\section{Experimental Procedures}

\subsection{Sol-Gel Preparation}

In this study, the hybrid silica-based sol-gel was synthesized from tetraethyl orthosilicate silane (TEOS) and trimethoxymethyl silane (MTMS) precursors, purchased from Sigma-Aldrich. The precursors were mixed in isopropyl alcohol by adding deionized (DI) water dropwise in a molar ratio of 18:14:17:220, respectively, until the hydrolyzing and condensation reactions. As mentioned in the previous work, the silica-based sol-gel mixture was then enhanced by adding the poly-siloxane (PSES) solution [10]. The base formula used was labelled as SHX-80. 
The benzimidazole-modified hybrid silica-based sol-gel was labelled as BZI-SHX-80 and prepared by encapsulating 3.5 vol. $\%$ of a 1:1 solution of ethanol and benzimidazole (BZI) (Sigma-Aldrich) in the base formula SHX-80, added dropwise while stirring. The formulation was then left for $24 \mathrm{~h}$.

\subsection{Substrate Preparation and Film Deposition}

The aluminum alloy substrates used were purchased from Q-Lab as Standard aluminum alloy AA2024-T3 Q-panels with dimensions of (102 $\mathrm{mm} \times 25 \mathrm{~mm} \times 1.6 \mathrm{~mm})$ [11]. The received Q-panels were washed with a commercial aluminum base surfactant cleaner, then rinsed with DI water, followed by acetone washing to remove the organic residues on the surface.

Then, the sol-gel was sprayed onto the pre-cleaned aluminum alloy substrates. The distance from the spraying gun to the surface was approximately $150 \mathrm{~mm}$. The coating was built up over three passes to keep the thickness standard for all samples at about $15 \pm 2 \mu \mathrm{m}$. After that, the coated samples were left in the air for $10 \mathrm{~min}$ before being annealed at $80{ }^{\circ} \mathrm{C}$ for $4 \mathrm{~h}$. Table 1 shows the experiment codes used to identify the samples.

Table 1. Sample identification table.

\begin{tabular}{ccccc}
\hline No. & Identifier & Formula Base Composite & (BZI) $v / v \%$ & Curing Temperature \\
\hline $1-$ & SHX-80 & TEOS + MTMS + PSX & - & $80{ }^{\circ} \mathrm{C}$ \\
$2-$ & ZBI-SHX-80 & TEOS + MTMS + PSX & $3.5 \%$ & $80{ }^{\circ} \mathrm{C}$ \\
$3-$ & Bare AA2024-T3 & - & - & - \\
\hline
\end{tabular}

\subsection{Coating Testing and Characterization}

Electrochemical tests were performed on the bare and coated samples to assess their corrosion resistance. Tests were conducted by using a Princeton Applied Research PARSTAT 2273. The corrosion performance of the sol-gel-coated and uncoated aluminum alloy was evaluated using electrochemical impedance spectroscopy (EIS) and potentiodynamic polarization (PDPS) scans. An area of $1.00 \mathrm{~mm}^{2}$ in the center of the samples in aerated $3.5 \%$ $\mathrm{NaCl}$ was tested. The tests were carried out at room temperature $\left(20 \pm 2{ }^{\circ} \mathrm{C}\right)$. The electrode potential was monitored for approximately $1 \mathrm{~h}$ before polarization in the electrolyte solution until stability. The sample was polarized with PDPS at a scanning rate of $1.667 \mathrm{mVs}^{-1}$ from the initial potential of $-250 \mathrm{mV}$ vs. OCP to $+750 \mathrm{mV}$ vs. SCE. The electrochemical impedance measurements were recorded between $100 \mathrm{kHz}$ and $10 \mathrm{MHz}$ with a sinusoidal AC RMS value of $10 \mathrm{mV}$ [12].

\section{Results and Discussion}

\subsection{ATR-FTIR for the BZI-SBX-80 Sol-Gel Chemical Composition}

The organic BZI was successfully incorporated into the SHX sol-gel base formula by comparing the infrared spectrum obtained from the BZI-SHX-80 coating to that of the unmodified SHX-80. This is enlarged in Figure 2. In the spectrum of the BZI-modified coating, several peaks are seen related to the BZI molecule. These peaks can be observed and were retained in the sol-gel-coated BZI-SBX-80 sample. They are as follows: weak imine $\mathrm{C}=\mathrm{N}$ stretching at $1564.5 \mathrm{~cm}^{-1}$; carbon double-bond $\mathrm{C}=\mathrm{C}$ stretching peaks at about $1477 \mathrm{~cm}^{-1}, 1458 \mathrm{~cm}^{-1}$, and $1408 \mathrm{~cm}^{-1}$, respectively. Similarly, the fingerprint of the aromatic amine stretching $\mathrm{C}-\mathrm{N}$ can be detected at $1364 \mathrm{~cm}^{-1}$ and $1300 \mathrm{~cm}^{-1}$, respectively, which can be used to confirm the benzimidazole's presence in the new sol-gel formula. The $\mathrm{C}-\mathrm{H}$ out-of-plane bending is characterized by the peaks at $768 \mathrm{~cm}^{-1}$ and $745 \mathrm{~cm}^{-1}$ [13]. 


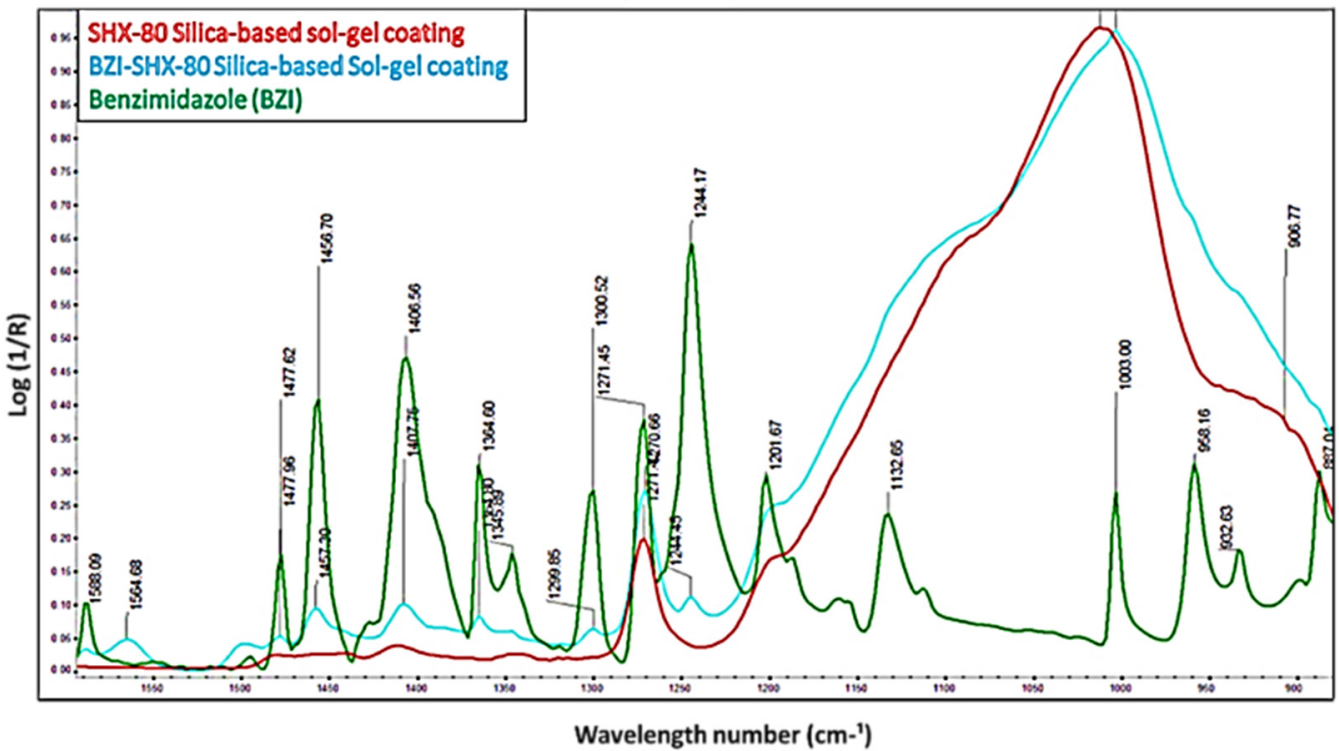

Figure 2. ATR-FTIR spectra, showing the effect of the BZI added to the SHX-80 sol-gel.

\subsection{Water Contact Angle of the SBX and BZI-SBX Coatings}

As shown in Figure 3, the measured water contact angle (WCA) of the base SHX-80 coating was about $67 \pm 2^{\circ}$, as shown in Figure $3 a$, and the measured WCA on the modified BZI-SHX-80 sol-gel coating was $88 \pm 4^{\circ}$, as shown in Figure $3 \mathrm{~b}$; the higher water contact angle recorded for the BZI-SHX-80 shows that its wettability is lower than that of the original SHX-80 [14].

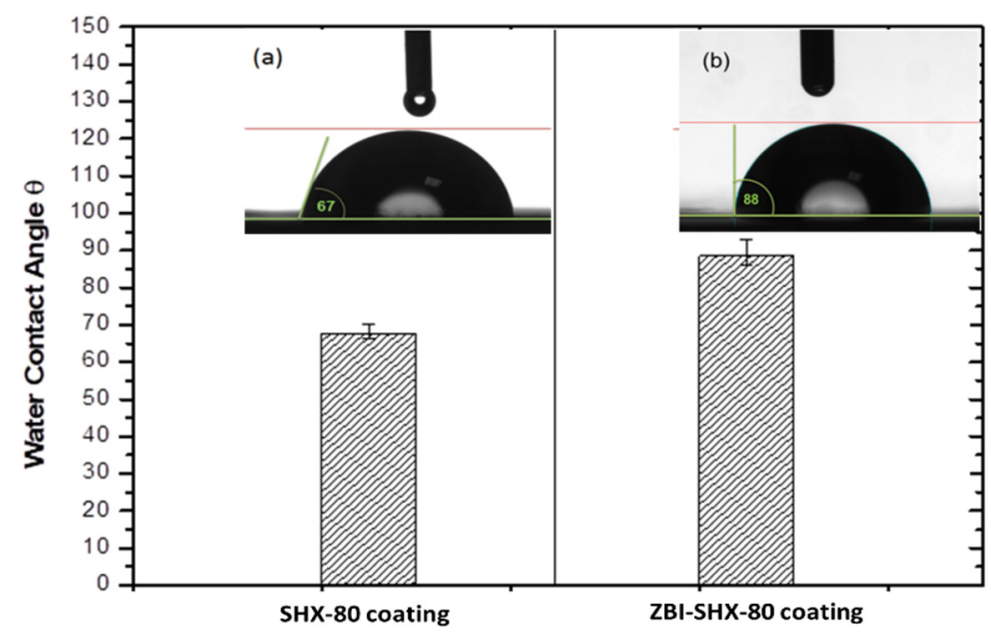

Figure 3. Bar chart showing the mean values of the WCA of the BZI-SHX-80 and SHX-80 coatings. Optical images showing water droplets on the (a) SHX-80 and (b) modified BZI-SHX-80 coatings.

\subsection{Potentiodynamic Polarization Scanning}

All coated samples displayed significantly improved performance compared to the bare AA2024-T3 sample. The corrosion potential $\left(\mathrm{E}_{\text {corr }}\right)$ and corrosion current density $\left(\mathrm{I}_{\text {corr }}\right)$ were obtained from PDPS, as shown in Figure 4 . The current density on the cathodic branch of the Tafel curve for all coated samples was reduced by more than four magnitudes when compared to the bare AA2024-T3. Nevertheless, the current density of the BZI-SHX-80coated sol-gel sample was the lowest, as it was reduced by seven orders of magnitude compared to the bare AA2024-T3. This reduction may be attributed to benzimidazole's surface activity and high electronegativity [5]. The SHX-80 sol-gel only showed a reduction in the anodic branch by about four and a half orders of magnitude less than the bare 
AA2024-T3. The corrosion current densities of the bare and coated samples were reduced to $5.98 \times 10^{-10} \mathrm{~A} / \mathrm{cm}^{2}$ for BZI-SHX-80 and $1.1 \times 10^{-9} \mathrm{~A} / \mathrm{cm}^{2}$ for SHX-80, respectively, compared to $7.1 \times 10^{-6} \mathrm{~A} / \mathrm{cm}^{2}$ for the bare AA2024-T3 alloy. The shift in $\mathrm{E}_{\text {corr }}$ indicates that the anode is inhibited to a greater degree than the cathode in the BZI-SHX 80 sol-gel mixture. This could be attributed to the active benzimidazole nitrogen atoms bridging the substrate surface $[5,6]$.

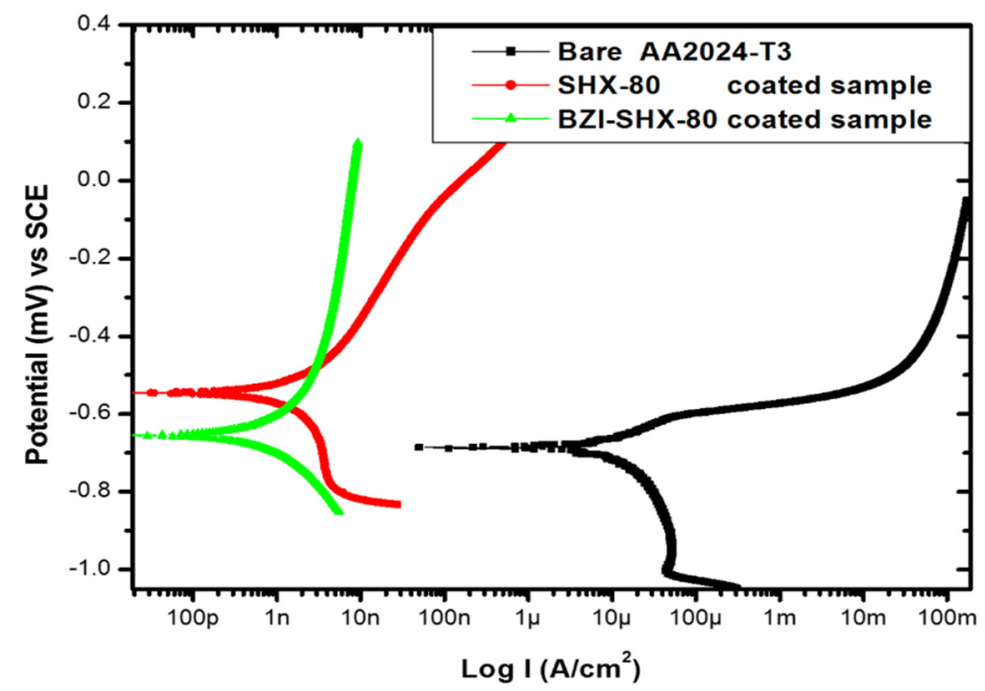

Figure 4. Polarization (PDPS) curves for the bare and sol-gel-coated samples with/without BZI in $3.5 \% \mathrm{NaCl}$.

\subsection{Electrochemical Impedance Spectroscopy}

3.4.1. Impedance Magnitude Bode Plots

As shown in Figure $5 a, b$, after the first hour of immersion, the overall impedance of the BZI-SHX-80 at low frequencies was higher by approximately two orders of magnitude compared to the SHX-80-coated samples, with values of $5.7 \times 10^{7} \mathrm{ohms} \mathrm{cm}^{-2}$ and $9.1 \times 10^{5} \mathrm{ohms} \mathrm{cm}^{-2}$ for BZI-SHX-80 and SHX-80, respectively.
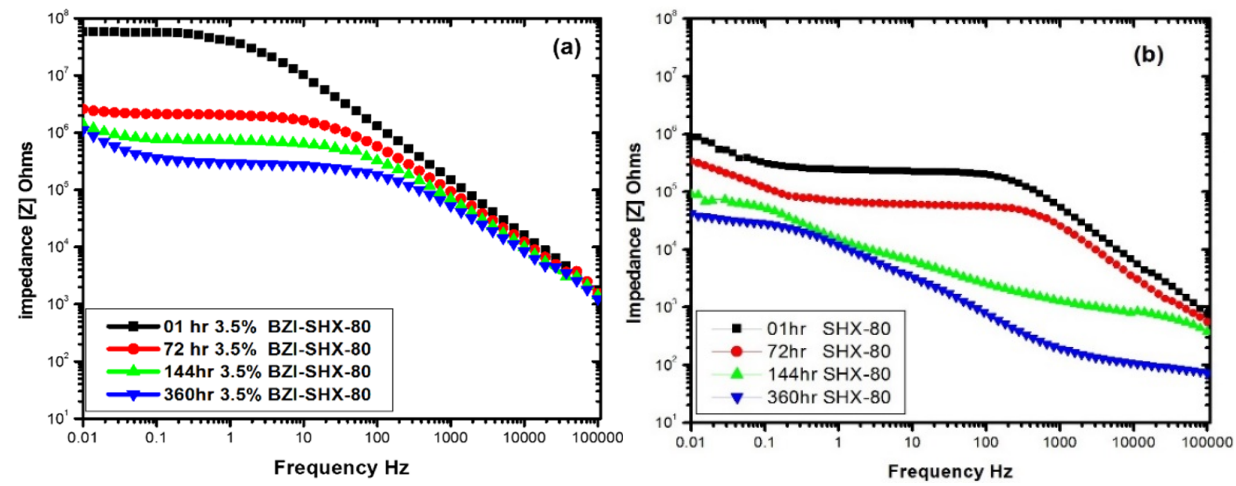

Figure 5. Impedance magnitude Bode plots for (a) BZI-SHX-80 and (b) SHX-80.

After $360 \mathrm{~h}$, the impedance of the BZI-SHX-80-coated samples dropped by about one and a half orders of magnitude; this could be due to the electrolyte diffusion and expansion of the pores in the sol-gel coating matrix. However, this drop was not reflected in the visible protection in the electrolyte, suggesting that the film of the sol-gel/BZI on the metal surface was stable [10].

A noticeable drop in impedance was observed for the SHX-80-coated sample at about $3.4 \times 10^{4} \mathrm{ohms} \mathrm{cm}^{-2}$ after $360 \mathrm{~h}$. This might be attributed to the reduction of the coating resistance due to the development of rounded pitting under the coatings. The high-frequency impedance also dropped by about one order of magnitude; this impedance 
is considered higher than that of the SBX-80 coating in the mid-frequency range between $10^{5} \mathrm{~Hz}$ and $10^{6} \mathrm{~Hz}$. This may be attributed to the coating's pores and the cracking that occurred.

\subsubsection{Using Nyquist Plots to Investigate the Corrosion-Protective Behavior}

Figure 6 shows the Nyquist plots for both the BZI-SHX-80- (Figure 6a) and the OASHX-80- (Figure $6 \mathrm{~b}$ ) coated samples from 1-360 h, respectively. The plots show that the BZI-SHX-80 has the maximum impedance. These plots were used to obtain the equivalent circuit modelling fit using the ZSimpwin electrochemical impedance spectroscopy (EIS) data analysis software. Tables 2 and 3 below demonstrate the fit data for the SHX-80 and the BZI-SHX-80 coatings after various immersion times. The equivalent circuits were used to simulate the corrosion reaction on the surface of the coated samples at $1 \mathrm{~h}, 48 \mathrm{~h}$ and $144 \mathrm{~h}$, respectively. In these circuits, instead of using an ideal capacitor (C), a time-constant element $(\mathrm{Q})$ was used to compare the current leakage in the capacitor and/or frequency dispersion effect of the alternating current signals [12]. The suggested equivalent circuits for each EIS plot after $144 \mathrm{~h}$ are provided in Figure 7 for both systems.
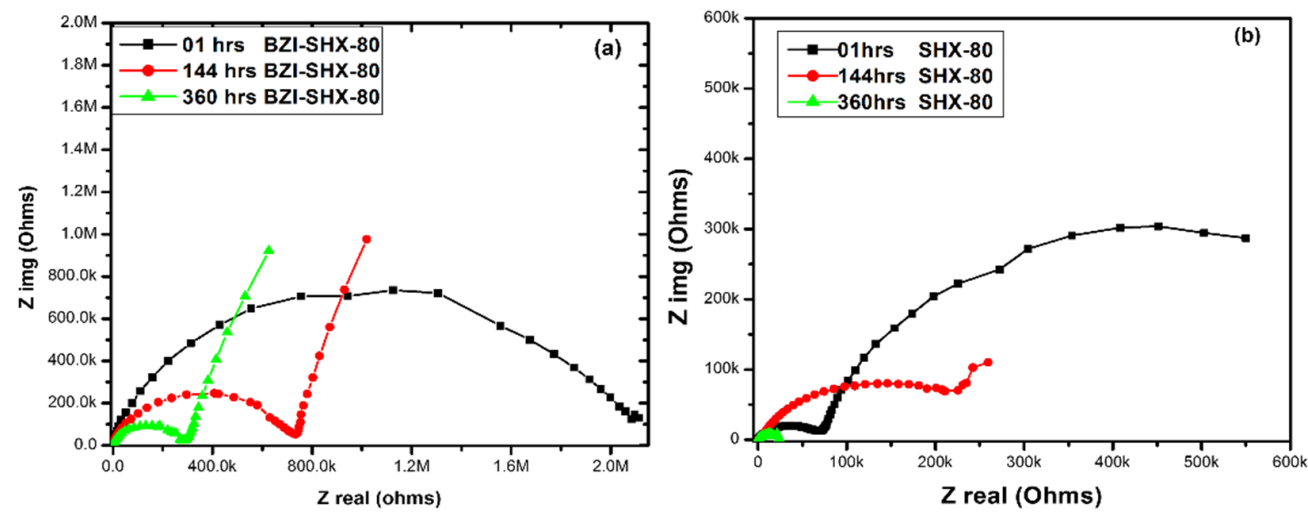

Figure 6. The Nyquist plots for the (a) BZI-SHX-80 coating and (b) SHX-80 coating systems.

Table 2. The fit data obtained from the EIS spectra for the BZI-SHX-80 sol-gel coating after various immersion times in $3.5 \mathrm{wt}$. \% NaCl solution.

\begin{tabular}{llccc}
\hline \multirow{2}{*}{ Circuit } & Element & $\mathbf{0 1}$ & $\mathbf{4 8}$ & $\mathbf{1 4 4}$ \\
\cline { 3 - 5 } & & $\mathbf{0}(\mathbf{Q}(\mathbf{R}(\mathbf{Q R})))$ & $\mathbf{R}(\mathbf{Q}(\mathbf{R}(\mathbf{Q}(\mathbf{R W}))))$ & $\mathbf{R}(\mathbf{Q}(\mathbf{R}(\mathbf{Q}(\mathbf{R W}))))$ \\
\cline { 3 - 5 } & $\mathrm{R}_{\mathrm{s}}$ & 105 & 160 & 201 \\
& $\mathrm{Q}_{\mathrm{ct}}$ & $1.471 \times 10^{-9}$ & $4.549 \times 10^{-9}$ & $9.148 \times 10^{-9}$ \\
$\mathrm{n}$ & 0.9626 & 0.887 & 0.8406 \\
$\mathrm{R}_{\mathrm{ct}}$ & $1.326 \times 10^{7}$ & $1.301 \times 10^{6}$ & $6.991 \times 10^{5}$ \\
$\mathrm{Q}_{\mathrm{iL}}$ & $3.453 \times 10^{-9}$ & $6.406 \times 10^{-8}$ & $9.016 \times 10^{-8}$ \\
$\mathrm{n}$ & 0.800 & 0.650 & 0.800 \\
$\mathrm{R}_{\mathrm{iL}}$ & $4.697 \times 10^{7}$ & $5.885 \times 10^{5}$ & $1.778 \times 10^{3}$ \\
$\mathrm{~W}$ & - & $4.349 \times 10^{-8}$ & $7.044 \times 10^{-10}$ \\
\hline
\end{tabular}

The element identifiers used for the equivalent circuits were solution resistance $\left(R_{s}\right)$, coating resistance $\left(R_{c t}\right)$, coating constant phase elements $\left(Q_{c t}\right)$, interfacial layer resistance $\left(R_{i L}\right)$, interfacial layer capacitance $\left(Q_{i L}\right)$, oxide layer (pitting) resistance $\left(R_{p}\right)$, oxide layer (pitting) capacitance $\left(\mathrm{Q}_{\mathrm{p}}\right)$, and the Warburg circuit element (W) [15]. 
Table 3. The fit data obtained from the EIS spectra for the SHX-80 sol-gel coating after various immersion times in $3.5 \mathrm{wt}$. \% NaCl solution.

\begin{tabular}{ccccc}
\hline \multirow{3}{*}{ Circuit } & & \multicolumn{2}{c}{ Immersion Time (H) } \\
\cline { 3 - 5 } & Element & $\mathbf{0 1}$ & $\mathbf{4 8}$ & $\mathbf{1 4 4}$ \\
\cline { 3 - 5 } & $\mathbf{R}(\mathbf{Q}(\mathbf{R}(\mathbf{Q R})))$ & $\mathbf{R}(\mathbf{Q}(\mathbf{R}(\mathbf{Q}(\mathbf{R}(\mathbf{Q R})))))$ & $\mathbf{R}(\mathbf{Q}(\mathbf{R}(\mathbf{Q}(\mathbf{R}(\mathbf{Q R})))))$ \\
\hline $\mathrm{R}_{\mathrm{s}}$ & 100 & 205 & 225 \\
$\mathrm{Q}_{\mathrm{ct}}$ & $1.079 \times 10^{-7}$ & $2.850 \times 10^{-7}$ & $4.771 \times 10^{-6}$ \\
$\mathrm{n}$ & 0.800 & 0.627 & 0.490 \\
$\mathrm{R}_{\mathrm{ct}}$ & $7.287 \times 10^{4}$ & 815 & 253 \\
$\mathrm{Q}_{\mathrm{iL}}$ & $4.933 \times 10^{-6}$ & $1.151 \times 10^{-6}$ & $3.912 \times 10^{-6}$ \\
$\mathrm{n}$ & 0.850 & 0.694 & 0.896 \\
$\mathrm{R}_{\mathrm{iL}}$ & $7.793 \times 10^{5}$ & $4.022 \times 10^{5}$ & $1.221 \times 10^{5}$ \\
& $\mathrm{Q}_{\mathrm{p}}$ & - & $7.364 \times 10^{-5}$ & $4.835 \times 10^{-5}$ \\
$\mathrm{n}$ & - & 0.900 & 0.455 \\
$\mathrm{R}_{\mathrm{p}}$ & - & $1.369 \times 10^{6}$ & $1 \times 10^{20}$ \\
\hline
\end{tabular}

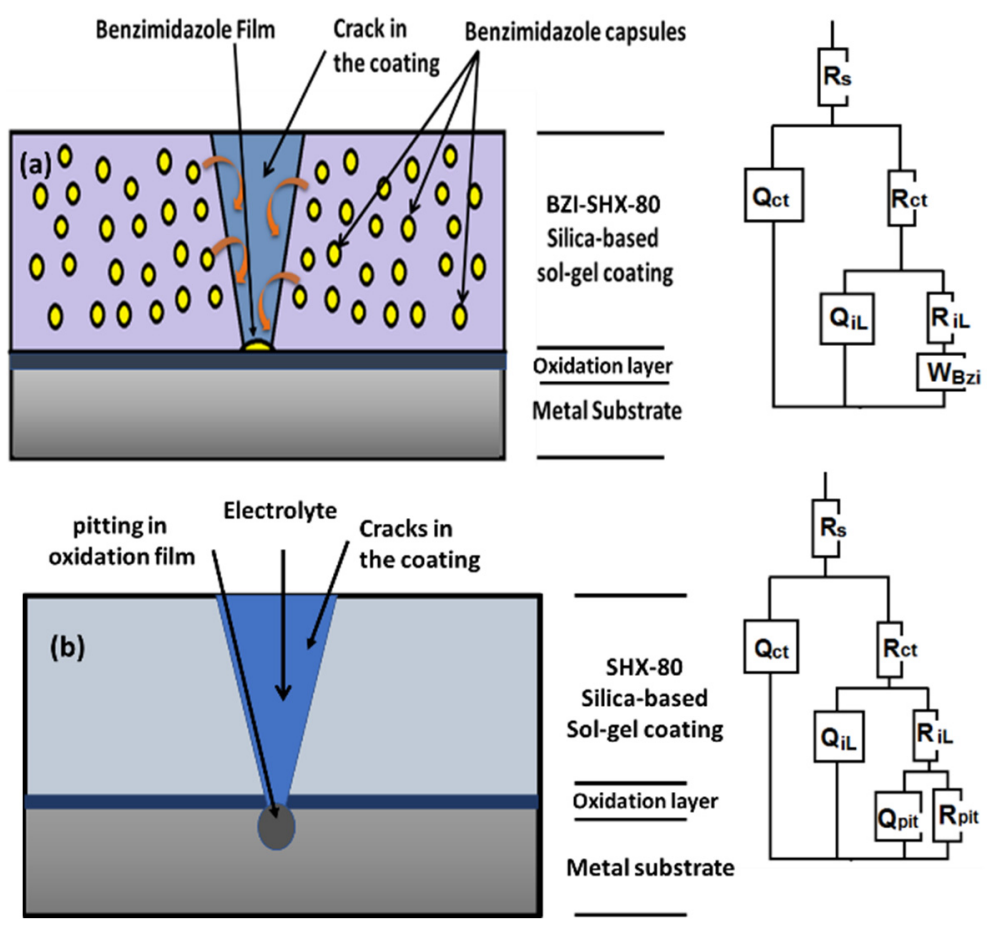

Figure 7. Schematic drawing of the hybrid silica-based system. (a) BZI-SHX-80 and (b) SHX-80 after $144 \mathrm{~h}$ of immersion in $3.5 \% \mathrm{NaCl}$ solution.

\subsection{Scanning Electron Microscopy Images after Immersion}

Figure 8 shows the surface morphology of the three samples, BZI-SHX-80 (Figure 8a), SHX-80 (Figure 8b), and bare alloy AA2024-T3 (Figure 8c).

As presented in Figure 8a, the BZI-SBX-80 coating showed excellent resistance to corrosion and cracks under similar circumstances. It was expected that the ZBI-SHX-80 would be more stable than the SHX-80, which may prevent the coating system's diffusion, in line with the benzimidazole self-healing inhibition properties.

As shown in Figure 8b, in the SHX-80-coated samples, cracks around 1-6 $\mu \mathrm{m}$ wide were observed on the surface of the coating, with some pitting corrosion under the coating. Due to the cracking of the coating, the cracks could adversely affect the barrier corrosion protection, which has implications for future performance under wet/dry cycling.

On the other hand, the bare sample AA2024-T3 was attacked by aggressive pitting corrosion after $360 \mathrm{~h}$ of immersion, as shown in Figure 8c. 

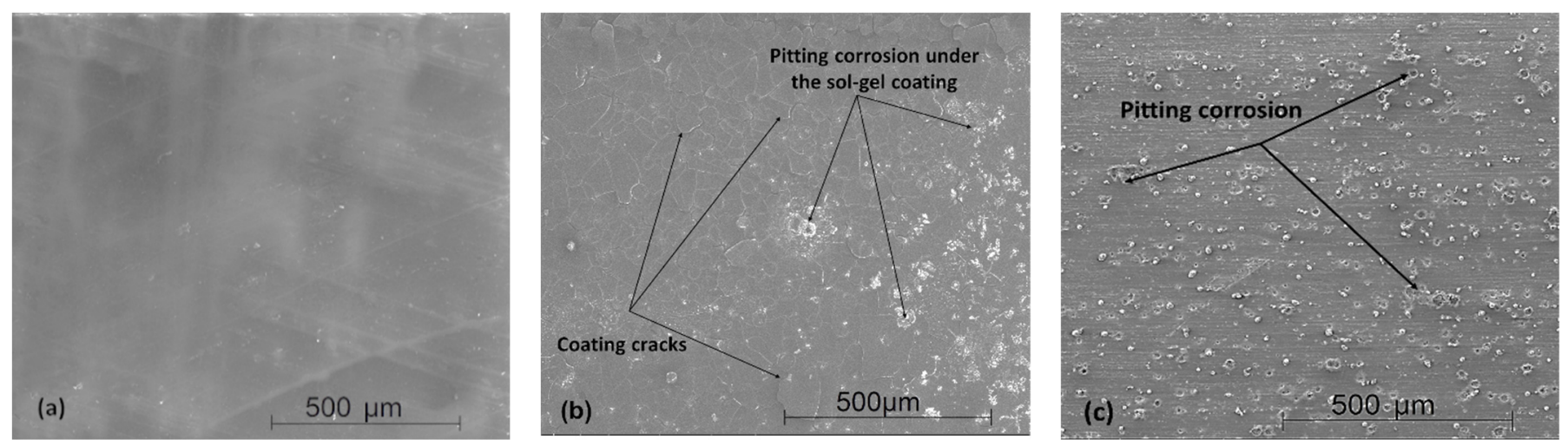

Figure 8. SEM surface images for the (a) BZI-SHX-80-coated sample, (b) SHX-80-coated sample, and (c) bare AA2024-T3 after $360 \mathrm{~h}$ of immersion in $3.5 \% \mathrm{NaCl}$ solution.

\section{Conclusions}

The base SHX sol-gel formula can provide moderate barrier protection without the presence of any inhibitor. The protection can last for at least $10 \mathrm{~d}$ in $3.5 \% \mathrm{NaCl}$ solution before cracks and pitting corrosion appear visually under the coating surface.

However, by encapsulating the benzimidazole in the silica-based sol-gel, excellent corrosion protection can be achieved, which can provide protection over two weeks without any signs of failure, including cracks and pitting corrosion. Adding benzimidazole as an inhibitor to the sol-gel matrix provides active protection due to the high electronegativity of the active azole group. This was demonstrated by the physical appearance and through AC impedance measurements. In addition, the benzimidazole-sol-gel coating revealed an excellent resistance to post cracking after a long immersion.

Author Contributions: Methodology, M.H.M., O.L., and N.F.; validation and testing M.H.M.; data analysis, M.H.M., N.F., and O.L.; FTIR support, M.H.M. and F.D.Z.; investigation, M.H.M.; resources, M.H.M., O.L., and N.F.; writing, original draft preparation, M.H.M.; writing, review and editing, M.H.M., O.L., F.D.Z., and N.F.; project supervision, N.F. and O.L. All authors have read and agreed to the published version of the manuscript.

Funding: This research was funded by the Libyan scholarship program as part of a Ph.D. project.

Institutional Review Board Statement: Not applicable.

Informed Consent Statement: Not applicable.

Data Availability Statement: The data are not publicly available. The data files are stored on the corresponding instruments and personal computers.

Acknowledgments: The authors would like to acknowledge the support of the Sheffield Hallam University in Material and Engineering Research Institute (MERI), as well as the Libyan Scholarship Program for the financial support.

Conflicts of Interest: The authors declare no conflict of interest.

\section{References}

1. Antonijevic, M.M.; Petrovic, M.B. Copper corrosion inhibitors. A review. Int. J. Electrochem. Sci. 2008, 3, 1-28.

2. Antonijevic, M.; Milic, S.; Petrovic, M.; Radovanovic, M.; Stamenkovic, A. The Influence of pH and Chlorides on Electrochemical Behavior of Copper in the Presence of Benzotriazole. Int. J. Electrochem. Sci. 2009, 4, 962-979.

3. Wright, J.B. The Chemistry of the Benzimidazoles. Chem. Rev. 1951, 48, 397-541. [CrossRef] [PubMed]

4. Gupta, P.K. Herbicides and fungicides. In Biomarkers in Toxicology; Elsevier Inc.: Amsterdam, The Netherlands, 2014; ISBN 9780124046306.

5. Gutiérrez, E.; Rodríguez, J.A.; Cruz-Borbolla, J.; Alvarado-Rodríguez, J.G.; Thangarasu, P. Development of a predictive model for corrosion inhibition of carbon steel by imidazole and benzimidazole derivatives. Corros. Sci. 2016, 108, 23-35. [CrossRef]

6. Obot, I.B.; Madhankumar, A.; Umoren, S.A.; Gasem, Z.M. Surface protection of mild steel using benzimidazole derivatives: Experimental and theoretical approach. J. Adhes. Sci. Technol. 2015, 29, 2130-2152. [CrossRef] 
7. Grillo, F.; Tee, D.W.; Francis, S.M.; Früchtl, H.A.; Richardson, N.V. Passivation of copper: Benzotriazole films on Cu(111). J. Phys. Chem. C 2014, 118, 8667-8675. [CrossRef]

8. Colreavy, J.; Duffy, B.; Varma, P.C.R.; Hayden, H.; Oubaha, M. Organosilane Coating Compositions and Use Thereof. United States US20100330380A1, 30 December 2010.

9. Vijaykumar, S.; Prakash, O.; Raghavan, S.; Ramachandra, K.; Reddy, D. Sol-Gel Coating Compositions Including Corrosion Inhibitor-Encapsulated Layered Metal Phosphates and Related Processes. United States US10421869B2, 24 September 2019.

10. Mussa, M.H.; Rahaq, Y.; Takita, S.; Farmilo, N. Study the Enhancement on Corrosion Protection by Adding PFDTES to Hybrid Sol-Gel on AA2024-T3 Alloy in 3.5\% NaCl Solutions. Albahit. J. Appl. Sci. 2021, 2, 61-68.

11. ASTM International ASTM Code B209-14 Standard Specification for Aluminum and Aluminum-Alloy Sheet and Plate; ASTM International: West Conshohocken, PA, USA, 2016; Volume 25, p. 16.

12. Tait, W.S. Electrochemical Impedance Spectroscopy Fundamentals, an Introduction to Electrochemical Corrosion Testing for Practicing Engineers and Scientists; Tait, W.S., Ed.; PairODocs Publications: Racine, WI, USA, 1994; ISBN 13-978-0966020700.

13. Mohan, S.; Sundaraganesan, N.; Mink, J. FTIR and Raman studies on benzimidazole. Spectrochim. Acta Part A Mol. Spectrosc. 1991, 47, 1111-1115. [CrossRef]

14. Kumar, D.; Wu, X.; Fu, Q.; Ho, J.W.C.; Kanhere, P.D.; Li, L.; Chen, Z. Development of durable self-cleaning coatings using organic-inorganic hybrid sol-gel method. Appl. Surf. Sci. 2015, 344, 205-212. [CrossRef]

15. Yabuki, A.; Yamagami, H.; Noishiki, K. Barrier and self-healing abilities of corrosion protective polymer coatings and metal powders for aluminum alloys. Mater. Corros. 2007, 58, 497-501. [CrossRef] 